\title{
Introduction of complementary foods in Sweden and impact of maternal education on feeding practices
}

\author{
Sofia Klingberg ${ }^{1,2, *}$, Johnny Ludvigsson ${ }^{1,} \uparrow$ and Hilde K Brekke ${ }^{1,3,} \dagger$ \\ 'Division of Pediatrics, Department of Clinical and Experimental Medicine, Linköping University, Linköping, Sweden: \\ ${ }^{2}$ Department of Public Health and Community Medicine, Section for Epidemiology and Social Medicine (EPSO), \\ Institute of Medicine, Sahlgrenska Academy, University of Gothenburg, PO Box 454, 40530 Gothenburg, \\ Sweden: ${ }^{3}$ Department of Nutrition, Institute of Basic Medical Sciences, Faculty of Medicine, University of Oslo, \\ Oslo, Norway
}

Submitted 30 May 2016: Final revision received 5 October 2016: Accepted 18 0ctober 2016: First published online 5 December 2016

\begin{abstract}
Objective: To describe the introduction of complementary foods in a populationbased cohort in relation to recommendations and explore the possible impact of maternal education on infant feeding practices.

Design: Prospective data from the All Babies in Southeast Sweden (ABIS) cohort study were used. The ABIS study invited all infants born in south-east Sweden during October 1997-October 1999 ( $n$ 21 700) to participate. A questionnaire was completed for 16022 infants. During the infants' first year parents continuously filed in a diary covering introduction of foods.

Setting: Sweden.

Subjects: Infants ( $n$ 9727) with completed food diaries.

Results: Potatoes, vegetables, fruits/berries and porridge were the foods first introduced, with a median introduction between 19 and 22 weeks, followed by introduction of meat, cow's milk, follow-on formula and sour milk/yoghurt between 24 and 27 weeks. Early introduction of any food, before 16 weeks, occurred for $27 \%$ of the infants and was more common in infants of mothers with low education. Overall, potatoes (14.7\%), vegetables (11.1\%), fruits/berries ( $8.5 \%)$, porridge $(7.4 \%)$ and follow-on formula $(2.7 \%)$ were the foods most frequently introduced early. The majority of infants $(\geq 70 \%)$ were introduced to potatoes, vegetables, fruits/berries and porridge during concurrent breast-feeding, but introduction during concurrent breast-feeding was less common in infants of mothers with low education.

Conclusions: Most infants were introduced to complementary foods timely in relation to recommendations. Low maternal education was associated with earlier introduction of complementary foods and less introduction during concurrent breast-feeding. Still, the results indicated exposure to fewer foods at 12 months in infants of mothers with low education.
\end{abstract}

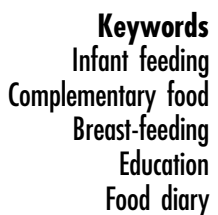

Since 2001, the WHO has recommended exclusive breast-feeding for the first 6 months of life ${ }^{(1)}$. Breast milk is the ideal food for optimal growth, development and health of the infant ${ }^{(2)}$. By 6 months of age the nutritional requirements of the infant, particularly the requirement for iron $^{(3)}$, call for addition of other foods and complementary feeding should be initiated. The WHO defines complementary feeding as the process of introducing other foods and liquids to the infant, when the nutritional requirements of the infant are no longer met solely by

$\dagger$ These authors acted as equivalent senior authors. breast milk ${ }^{(4)}$. Thus, foods given in addition to breast milk are called complementary foods. Timely introduction of complementary foods may be essential not only for covering the nutritional needs of the infant, but also for food acceptance later in childhood ${ }^{(5)}$. Additionally, although there are discrepancies in the literature, the general timing of introduction of complementary foods may affect risk of obesity ${ }^{(6)}$, while the timing of introduction of specific foods has been suggested to affect the risk of type 1 diabetes $^{(7)}$ and food allergy ${ }^{(8)}$. Furthermore, introduction of gluten during concurrent breast-feeding has been suggested to offer protection against coeliac disease ${ }^{(9)}$. However, 
a recent position paper from the European Society for Pediatric Gastroenterology, Hepatology and Nutrition stated that although breast-feeding has other health effects, introduction of gluten during concurrent breast-feeding, as compared with introduction to gluten after weaning, has not been shown to be associated with a reduced risk of coeliac disease ${ }^{(10)}$. Yet, it could be hypothesized that concurrent breast-feeding during introduction of specific foods or allergens could offer protective effect against development of immunological diseases.

In 1997 a large prospective observational cohort study of all children born in the south-east of Sweden, the All Babies in Southeast Sweden (ABIS) study ${ }^{(11)}$, was initiated. At that time, the Swedish National Institute of Public Health recommended that complementary foods were introduced at 4 to 6 months of age, starting with potatoes, vegetables and fruits and then continuing with meat, fish and eggs ${ }^{(12)}$. The rationale for this order was more based on cultural tradition than on scientific evidence. Additionally, parents were recommended to wait with introduction of gluten until the infant was 6 months old ${ }^{(12)}$. A new pamphlet with updated recommendations on infant feeding was published first in $1998^{(13)}$, and then in $1999^{(14)}$ when the Swedish National Food Agency took over the responsibility for these recommendations. Essentially the only recommendation that was changed in these updated recommendations was that gluten should be introduced slowly from 4 months of age and preferably during concurrent breast-feeding. The new recommendation regarding timing of gluten introduction was based on research showing that the incidence of coeliac disease had increased dramatically in Sweden during the $1980 \mathrm{~s}^{(15)}$, when recommendations during the preceding decades successively had been postponed from 1 month in the 1960 s to 6 months in $1982^{(16)}$. Current guidelines ${ }^{(17)}$, published in 2012, recommend exclusive breast-feeding for 6 months with introduction of tiny tastes of any food (including gluten-containing foods) from 4 months of age as long as these tastes do not compete with breast-feeding.

Earlier we investigated breast-feeding duration, introduction of cow's milk and gluten in the ABIS cohort using retrospectively collected data ${ }^{(18)}$, but more detailed information about the timing of introduction of complementary foods in population-based samples of Swedish infants is lacking. Previously, we also showed that parental education, especially maternal education, was inversely related to intake frequency of sweets and pastries at 1 year of age as well as early introduction to sugar-sweetened drinks ${ }^{(19)}$ and that low maternal education predicted shorter duration of exclusive breast-feeding ${ }^{(20)}$, which calls for further investigation of how introduction of complementary feeding in the ABIS cohort is affected by maternal education. Other studies have also shown different socio-economic characteristics to influence infant feeding practices in terms of both the timing of first introduction to complementary foods ${ }^{(21-24)}$ as well as the timing of introduction of some specific foods ${ }^{(25,26)}$, but without covering all food groups.
Therefore, the aim of the present paper was to thoroughly describe the introduction of complementary feeding using prospectively collected data in a large population-based Swedish cohort with regard to timing of introduction of different foods and food groups, and to describe whether public health recommendations were followed. Additionally we wanted to explore the possible impact of maternal education on infant feeding practices.

\section{Methods}

\section{Study population}

The present paper is based on the ABIS cohort. The region of south-east Sweden included the counties of Östergötland, Småland, Blekinge and Öland. Parents of all the 21700 babies born in this region during 1 October 1997 to 1 October 1999 were invited to participate. The parents were informed about the study during pregnancy and were recruited at the maternity ward ${ }^{(11)}$. A total of 16022 mothers completed a baseline study questionnaire after delivery, before leaving the maternity ward, or at home. If the study questionnaire was filled in at home it was returned to a doctor or a nurse at the regular infant health check-up within a week from birth. Since then the cohort has been followed through several re-examinations at different ages of the child ${ }^{(27)}$. In the present study our sample is based on 9727 children whose parents, in addition to the baseline questionnaire, also completed a food diary (described below) during their first year of life. Some information was also used from a follow-up questionnaire completed at 1 year of age for 8792 of these children participating in the food diary.

\section{Introduction to complementary foods}

During the infants' first year, the parents were instructed to fill in a detailed food diary to record the duration of breast-feeding and the timing of introduction of complementary feeding. The food diary contained a list of twenty-five specified foods and food groups including breast milk, infant formula, different types of follow-on formula or gruel (with gluten; without gluten; soya; wholegrain; corn), different types of porridge (with gluten; oatmeal; rice; semolina), cheese, cow's milk, sour milk and yoghurt, bread with gluten, pasta, potatoes, rice, fruits and berries, sugar-containing foods (fruit drinks and soda; sugar and sweets), vegetables, meat, fish and eggs. Follow-on formula in Sweden is made of milk and cereals and is typically bought as an industrially produced powder and mixed with water. The parents were instructed to register both the date of the first introduction and, if applicable, also the date of termination. For ten of the specified foods additional questions were asked on the regularity of consumption after introduction of the food. These ten foods were breast milk, infant formula, follow-on formula containing soya, follow-on formula 
containing gluten, porridge containing gluten and cow's milk, bread containing gluten, pasta containing gluten, fish and eggs. Data on the regularity of consumption were not, however, used in the present study.

The questionnaire at the 1-year follow-up included some questions about breast-feeding and feeding practices during the infants' first year, thus retrospectively overlapping the questions of the food diary. Where data on termination of breast-feeding was missing in the food diary, data from the 1-year follow-up questionnaire were used.

\section{Parental socio-economic and lifestyle variables}

Descriptive information about the parents was assessed through the baseline questionnaire. Parental age (continuous) at birth of the child was calculated from date of birth for both parents. Maternal and paternal education was divided into three categories: low education (compulsory school or less); intermediate education (practical upper secondary school, theoretical upper secondary school and folk high school); and high education (university 1-3 years and university degree). Information on maternal smoking during pregnancy was dichotomous (yes/no). Proportions of mothers and fathers, respectively, born in Sweden were reported, as well as the proportion of children not having any siblings. Marital status at time of birth was reported by three categories: single mother; cohabiting; and married.

\section{Statistical analyses}

Since the aim of the present study was to investigate the timing of introduction of complementary foods during the first year, only introductions during the first $365 \mathrm{~d}$ were considered in the analyses. Timing of introduction of complementary foods is mainly presented in weeks, but in figures timing is shown in months. Each month was considered to be four weeks. Introduction of complementary foods and weaning often take place concurrently over several weeks ${ }^{(24)}$. Thus, introduction of complementary foods during concurrent breast-feeding was defined with a $30 \mathrm{~d}$ overlap of breast-feeding, i.e. introduction was initiated at least $30 \mathrm{~d}$ before termination of breast-feeding.

Differences in continuous variables between two groups were examined by the independent-samples $t$ test. Differences in categorical variables were examined by the $\chi^{2}$ test. Since timing of introduction was not normally distributed, the time of introduction is presented as median, 25th and 75th percentile. Furthermore, the association between timing of introduction of foods and maternal education (three groups) was examined by the nonparametric Kruskal-Wallis test. When the overall KruskalWallis was significant, post hoc tests were performed.

All statistical analyses were performed in the statistical software package IBM SPSS Statistics Version 20.0. All tests were two-sided. To account for multiple testing, a $P$ value of $<0.001$ was considered significant.

\section{Results}

Detailed food diaries were available for 9727 children. Table 1 shows the representativeness of the food diary participants compared with the whole original cohort ( $n$ 16 022). Although differences between participants and non-participants mostly were small, the parents who chose to fill in the food diary were older and more often born in Sweden and the mothers had higher education and were less likely to smoke during pregnancy. Furthermore, higher proportions of the children participating in the food diary had married parents and were more often the first child.

Table 2 shows the timing of introduction of infant formula and complementary foods during the first year. Infant formula was introduced to half of the children during the first year and the median age for introduction was 7 weeks. Potatoes, vegetables, fruits and berries and porridge were the first foods to be introduced, with a median introduction between weeks 19 and 22. Thereafter meat, cow's milk, follow-on formula, sour milk and yoghurt were introduced between weeks 24 and 27, and followed by introduction of bread, fish, rice and pasta between weeks 28 and 34. The last foods to be introduced were cheese, sugar-containing foods and eggs, with a median introduction between weeks 35 and 39. The proportion of children being introduced to the foods during concurrent breast-feeding varied and decreased with increasing age at introduction. Early introduction, i.e. any complementary food before 16 weeks ( 4 months) of age, occurred for $27 \%$ of the infants (data not shown). Overall, potatoes $(14.7 \%)$, vegetables $(11.1 \%)$, fruits/berries ( $8.5 \%)$, porridge $(7 \cdot 4 \%)$ and follow-on formula $(2 \cdot 7 \%)$ were the foods most frequently introduced early. Followon formula was introduced to $3.7 \%$ of the infants before 16 weeks ( 4 months) of age. Figure 1 illustrates the cumulative proportion of infants being introduced to different foods and food groups and the proportion of breast-fed infants during the first 12 months. Most foods showed a steep increase in introduction between month 4 and month 7. However, for some foods, such as fish, cheese, sugar-containing foods and eggs, the pattern was different, with a slower rate of introduction. More than $90 \%$ of the children were introduced to potatoes, vegetables, fruits and berries, porridge, meat, milk products, bread and pasta during their first 12 months.

Table 3 shows the timing of introduction of complementary foods and food groups by maternal education. Several significant differences in timing were observed between different levels of maternal education. Generally, lower education was associated with earlier introduction and this pattern was evident for fruits and berries, cow's milk, follow-on formula, fish, rice, pasta, cheese and sugar-containing foods. The proportion of infants introduced to complementary foods early, i.e. before 16 weeks ( 4 months), differed significantly by maternal education $(P<0.001$; data not shown). About $41 \%$ of infants of 
Table 1 Characteristics of the parents at delivery for the parents of the initial cohort, the parents of the children participating in the food diary and the parents of the children not participating in the food diary, All Babies in Southeast Sweden (ABIS) study

\begin{tabular}{|c|c|c|c|c|c|c|c|}
\hline & \multicolumn{2}{|c|}{$\begin{array}{l}\text { Initial cohort } \\
(n 16022)\end{array}$} & \multicolumn{2}{|c|}{$\begin{array}{l}\text { Food diary participants } \\
\text { ( }(\text { 9727) }\end{array}$} & \multicolumn{2}{|c|}{$\begin{array}{l}\text { Food diary dropouts } \\
\qquad(n \text { 6295) }\end{array}$} & \multirow{2}{*}{$\begin{array}{l}P \text { value* for difference } \\
\text { between sub-samples }\end{array}$} \\
\hline & Mean & SD & Mean & SD & Mean & SD & \\
\hline Maternal age (years) & $29 \cdot 6$ & $4 \cdot 6$ & $29 \cdot 7$ & 4.5 & $29 \cdot 3$ & 4.8 & $<0.001$ \\
\hline \multirow[t]{2}{*}{ Paternal age (years) } & $32 \cdot 0$ & $5 \cdot 4$ & $32 \cdot 2$ & $5 \cdot 3$ & 31.8 & $5 \cdot 7$ & $<0.001$ \\
\hline & $\%$ & $n$ & $\%$ & $n$ & $\%$ & $n$ & \\
\hline \multicolumn{8}{|l|}{ Maternal education } \\
\hline Low & $37 \cdot 1$ & 5943 & $6 \cdot 8$ & 660 & $11 \cdot 3$ & 713 & $<0.001$ \\
\hline Intermediate & $30 \cdot 8$ & 4939 & $59 \cdot 3$ & 5764 & 59.5 & 3745 & \\
\hline High & $31 \cdot 6$ & 5063 & $33 \cdot 5$ & 3262 & 28.6 & 1801 & \\
\hline Paternal education & & & & & & & $<0.01$ \\
\hline Low & 33.8 & 5411 & $12 \cdot 6$ & 1225 & 14.5 & 912 & \\
\hline Intermediate & $40 \cdot 2$ & 6439 & 61.5 & 5982 & $59 \cdot 2$ & 3729 & \\
\hline High & $24 \cdot 1$ & 3859 & $24 \cdot 3$ & 2362 & 23.8 & 1497 & \\
\hline Maternal smoking during pregnancy & $11 \cdot 1$ & 1776 & $8 \cdot 8$ & 858 & 14.6 & 918 & $<0.001$ \\
\hline Mother born in Sweden & 93.2 & 14938 & 94.6 & 9200 & $91 \cdot 2$ & 5738 & $<0.001$ \\
\hline Father born in Sweden & $92 \cdot 4$ & 14803 & 93.8 & 9120 & $90 \cdot 3$ & 5683 & $<0.001$ \\
\hline First child & $37 \cdot 7$ & 6048 & 39.9 & 3877 & 34.5 & 2171 & $<0.001$ \\
\hline Marital status at birth of child & & & & & & & $<0.001$ \\
\hline Single mother & $2 \cdot 1$ & 339 & 1.6 & 156 & $2 \cdot 9$ & 183 & \\
\hline Co-habitant & $55 \cdot 3$ & 8864 & 54.8 & 5327 & $56 \cdot 2$ & 3537 & \\
\hline Married & $42 \cdot 3$ & 6771 & 43.4 & 4220 & 40.5 & 2551 & \\
\hline Child is a girl & $48 \cdot 2$ & 7729 & 48.4 & 4712 & 47.9 & 3017 & 0.35 \\
\hline
\end{tabular}

${ }^{*}$ Independent-samples $t$ test for continuous variables; otherwise $x^{2}$ test.

Table 2 Timing of introduction of infant formula and complementary foods during the first 12 months, All Babies in Southeast Sweden (ABIS) study $(n$ 9727)

\begin{tabular}{|c|c|c|c|c|c|c|}
\hline \multirow[b]{2}{*}{ Food or food group } & \multirow[b]{2}{*}{$\begin{array}{c}\text { Median time } \\
\text { of introduction (weeks) }\end{array}$} & \multirow[b]{2}{*}{$\begin{array}{l}\text { 25th-75th } \\
\text { percentile }\end{array}$} & \multicolumn{2}{|c|}{$\begin{array}{l}\text { Introduced before } 16 \text { weeks } \\
\text { (4 months) }\end{array}$} & \multicolumn{2}{|c|}{$\begin{array}{l}\text { Introduced during first year and during } \\
\text { breast-feeding } \dagger\end{array}$} \\
\hline & & & $\%$ & $n$ & $\%$ & $n$ \\
\hline Infant formula & $7 \cdot 3$ & $0.9-16.9$ & $37 \cdot 7$ & 3665 & $38 \cdot 7$ & 3761 \\
\hline Potatoes & 18.9 & $17 \cdot 4-22 \cdot 0$ & $14 \cdot 7$ & 1430 & 74.6 & 7254 \\
\hline Vegetables & $19 \cdot 6$ & $17 \cdot 9-23 \cdot 0$ & $11 \cdot 1$ & 1082 & $72 \cdot 2$ & 7027 \\
\hline Fruits and berries & $21 \cdot 4$ & $18 \cdot 7-24.9$ & 8.5 & 826 & $70 \cdot 1$ & 6815 \\
\hline Porridge & $21 \cdot 6$ & $18 \cdot 6-25.9$ & 7.4 & 724 & 69.9 & 6797 \\
\hline Meat & $24 \cdot 0$ & $21 \cdot 9-27 \cdot 1$ & $1 \cdot 2$ & 120 & $64 \cdot 1$ & 6238 \\
\hline Milk & $26 \cdot 1$ & $22 \cdot 9-30 \cdot 0$ & 1.9 & 181 & $56 \cdot 2$ & 5469 \\
\hline Follow-on formula & $26 \cdot 4$ & $24 \cdot 6-30 \cdot 7$ & 3.7 & 357 & $45 \cdot 2$ & 4401 \\
\hline Sour milk and yoghurt & $27 \cdot 3$ & $24 \cdot 3-31 \cdot 6$ & 1.4 & 136 & 51.9 & 5047 \\
\hline Bread & $28 \cdot 1$ & $23 \cdot 9-33 \cdot 4$ & $2 \cdot 0$ & 195 & $51 \cdot 6$ & 5019 \\
\hline Fish & $31 \cdot 1$ & $25 \cdot 9-38 \cdot 3$ & 0.4 & 43 & $32 \cdot 4$ & 3151 \\
\hline Rice & $33 \cdot 1$ & $27 \cdot 7-36 \cdot 3$ & 0.9 & 87 & $36 \cdot 6$ & 3556 \\
\hline Pasta & 34.0 & $29 \cdot 9-36 \cdot 6$ & 0.5 & 53 & 35.4 & 3445 \\
\hline Cheese & $35 \cdot 0$ & $30 \cdot 1-40 \cdot 3$ & 0.5 & 44 & $25 \cdot 7$ & 2497 \\
\hline Sugar-containing foods & $36 \cdot 1$ & $28.4-43.0$ & $2 \cdot 1$ & 202 & 21.3 & 2073 \\
\hline Eggs & $38 \cdot 7$ & $32 \cdot 7-44 \cdot 7$ & 0.2 & 24 & $14 \cdot 6$ & 1416 \\
\hline
\end{tabular}

*Based on those introduced to the respective foods or food groups during the first year.

$\dagger$ Breast-fed $\geq 30 \mathrm{~d}$ after introduction.

mothers with low education were introduced early, while 29 and $21 \%$ of infants of mothers with intermediate and high education, respectively, were introduced early.

For all foods, except fish, the proportion of children introduced during the first year differed across categories of maternal education ( $P<0 \cdot 001$; Fig. 2). Generally, the proportion of children introduced to the respective foods at age 1 year was higher in children of mothers with higher education. For infant formula and sugar-containing foods the relationship was reversed, however, so that increasing maternal education was associated with fewer children introduced. The proportion of children introduced to complementary foods during concurrent breast-feeding also differed across categories of maternal education for all foods $(P<0 \cdot 001)$ except for sugar-containing foods. Higher maternal education was associated with an increased 


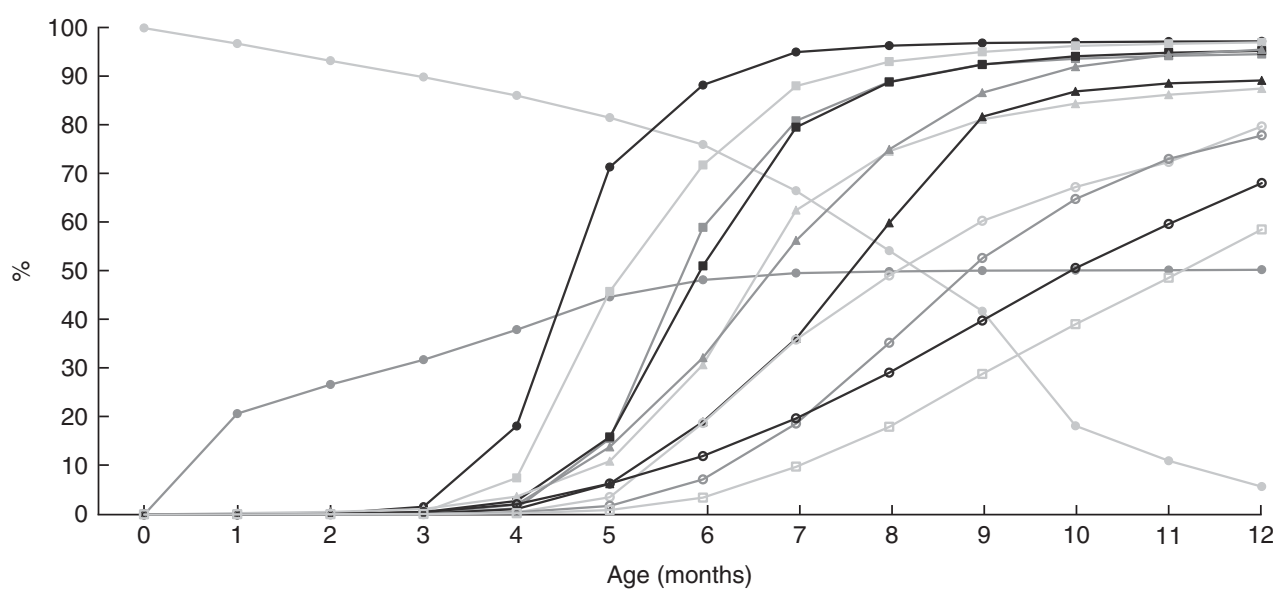

Fig. 1 Cumulative proportion of infants introduced to different foods and food groups and the proportion of infants being breast-fed during the first 12 months, All Babies in Southeast Sweden (ABIS) study (n 9727): ——, breast-feeding; —- , infant formula;

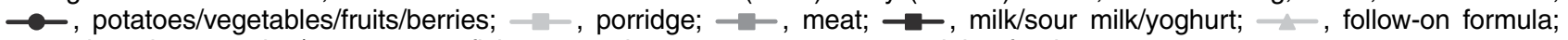

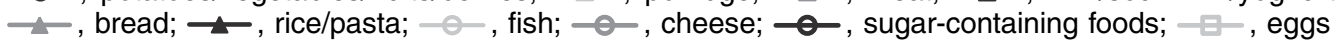

Table 3 Timing of introduction of infant formula and complementary foods during the first 12 months by maternal education, All Babies in Southeast Sweden (ABIS) study ( $n$ 9727)

\begin{tabular}{|c|c|c|c|c|c|c|c|}
\hline \multirow[b]{2}{*}{ Food or food group } & \multicolumn{6}{|c|}{ Median time of introduction (weeks) } & \multirow[b]{2}{*}{$P$ value } \\
\hline & $\begin{array}{l}\text { Low maternal } \\
\text { education }\end{array}$ & $\begin{array}{l}\text { 25th-75th } \\
\text { percentile }\end{array}$ & $\begin{array}{c}\text { Intermediate maternal } \\
\text { education }\end{array}$ & $\begin{array}{l}\text { 25th-75th } \\
\text { percentile }\end{array}$ & $\begin{array}{l}\text { High maternal } \\
\text { education }\end{array}$ & $\begin{array}{l}\text { 25th-75th } \\
\text { percentile }\end{array}$ & \\
\hline Infant formula & $6 \cdot 1$ & $1 \cdot 7-13 \cdot 6$ & $7 \cdot 6$ & $1 \cdot 1-16 \cdot 9$ & $6 \cdot 9$ & $0.4-17.6$ & 0.38 \\
\hline Potatoes & 19.0 & $17 \cdot 1-23 \cdot 3$ & 18.7 & $17 \cdot 4-22 \cdot 0$ & $19 \cdot 0$ & $17 \cdot 6-22 \cdot 0$ & 0.002 \\
\hline Vegetables & 19.9 & $17 \cdot 4-24 \cdot 7$ & 19.4 & $17 \cdot 7-23 \cdot 0$ & $19 \cdot 6$ & $18 \cdot 0-22 \cdot 9$ & 0.06 \\
\hline Fruits and berries & $20 \cdot 7 \dagger$ & $17 \cdot 8-25 \cdot 1$ & $21.3 \S$ & $18 \cdot 6-24.9$ & 21.6 & $19 \cdot 3-24 \cdot 9$ & $<0.001$ \\
\hline Porridge & 21.4 & $18 \cdot 1-26 \cdot 1$ & 21.7 & $18.4-25.9$ & 21.6 & $18 \cdot 7-25 \cdot 7$ & 0.45 \\
\hline Meat & $24 \cdot 0$ & $21 \cdot 5-29 \cdot 0$ & $23.7 \S$ & $21 \cdot 7-27 \cdot 0$ & 24.4 & $22 \cdot 1-27 \cdot 3$ & $<0.001$ \\
\hline Milk & $25 \cdot 1 \dagger$, & $21.6-28.9$ & $26.0 \S$ & $22 \cdot 7-29 \cdot 7$ & $26 \cdot 7$ & $23 \cdot 9-30 \cdot 7$ & $<0.001$ \\
\hline Follow-on formula & $25 \cdot 7 \dagger, \ddagger$ & $20 \cdot 7-29 \cdot 4$ & $26 \cdot 3 \S$ & $24 \cdot 3-30 \cdot 3$ & $27 \cdot 1$ & $25 \cdot 4-31.9$ & $<0.001$ \\
\hline Sour milk and yoghurt & 27.0 & $22 \cdot 9-31 \cdot 6$ & $27 \cdot 1 \S$ & $24 \cdot 1-31 \cdot 6$ & $27 \cdot 7$ & $24 \cdot 9-31.7$ & $<0.001$ \\
\hline Bread & $27 \cdot 4$ & $23 \cdot 0-33 \cdot 6$ & 28.4 & $24 \cdot 0-33.6$ & $27 \cdot 7$ & $23 \cdot 6-33 \cdot 0$ & 0.02 \\
\hline Fish & 29.3†,‡ & $24 \cdot 1-35 \cdot 9$ & $30.6 \S$ & $25 \cdot 6-37 \cdot 6$ & $32 \cdot 1$ & $26 \cdot 7-39 \cdot 3$ & $<0.001$ \\
\hline Rice & $31.6 \dagger, \ddagger$ & $25 \cdot 4-35 \cdot 4$ & 33.0 & $27 \cdot 7-36 \cdot 1$ & 33.6 & $28 \cdot 3-36 \cdot 7$ & $<0.001$ \\
\hline Pasta & $32 \cdot 6 \dagger, \ddagger$ & $26 \cdot 6-35 \cdot 4$ & $33.7 \S$ & $29 \cdot 4-36 \cdot 3$ & 34.4 & $30 \cdot 7-37 \cdot 1$ & $<0.001$ \\
\hline Cheese & $33.7 \dagger$ & $27 \cdot 9-39 \cdot 1$ & $34.9 \S$ & $29 \cdot 9-40 \cdot 1$ & $35 \cdot 4$ & $30.9-40.6$ & $<0.001$ \\
\hline Sugar-containing foods & $31.6 \dagger, \ddagger$ & $22 \cdot 6-40 \cdot 7$ & $35.7 \S$ & $27 \cdot 7-42 \cdot 4$ & $37 \cdot 7$ & $30 \cdot 8-44 \cdot 1$ & $<0.001$ \\
\hline Eggs & 37.7 & $30 \cdot 5-44 \cdot 1$ & 38.7 & $32 \cdot 6-44.9$ & 38.9 & $33 \cdot 1-44 \cdot 7$ & 0.02 \\
\hline
\end{tabular}

*Based on those introduced to the respective foods or food groups during the first year.

†Significant difference between low and high maternal education.

¥Significant difference between low and intermediate maternal education.

$\S$ Significant difference between intermediate and high maternal education.

proportion of children being introduced during concurrent breast-feeding. The cumulative proportion of children being breast-fed, introduced to infant formula and followon formula, respectively, according to maternal education is shown in Fig. 3. The proportion being breast-fed and the proportion introduced to infant formula, according to maternal education, showed inverse patterns. Lower maternal education was associated with earlier cessation of breast-feeding and higher proportions of infants introduced to infant formula and follow-on formula. Differences in these variables across categories of maternal education were significant at both 4 months and 6 months $(P<0 \cdot 001)$. Figure 4 shows the cumulative proportion of children introduced to milk, sour milk and yoghurt, fish and eggs over the first 12 months according to maternal education. Proportions of infants introduced to fish and milk, sour milk and yoghurt differed significantly across categories of maternal education at both 4 and 6 months $(P<0 \cdot 001)$ and lower maternal education was associated with higher proportions introduced. Maternal education did not seem to influence the introduction of eggs.

\section{Discussion}

In the present study we describe the introduction of complementary feeding in a large cohort of Swedish infants with emphasis on the timing of introduction of 


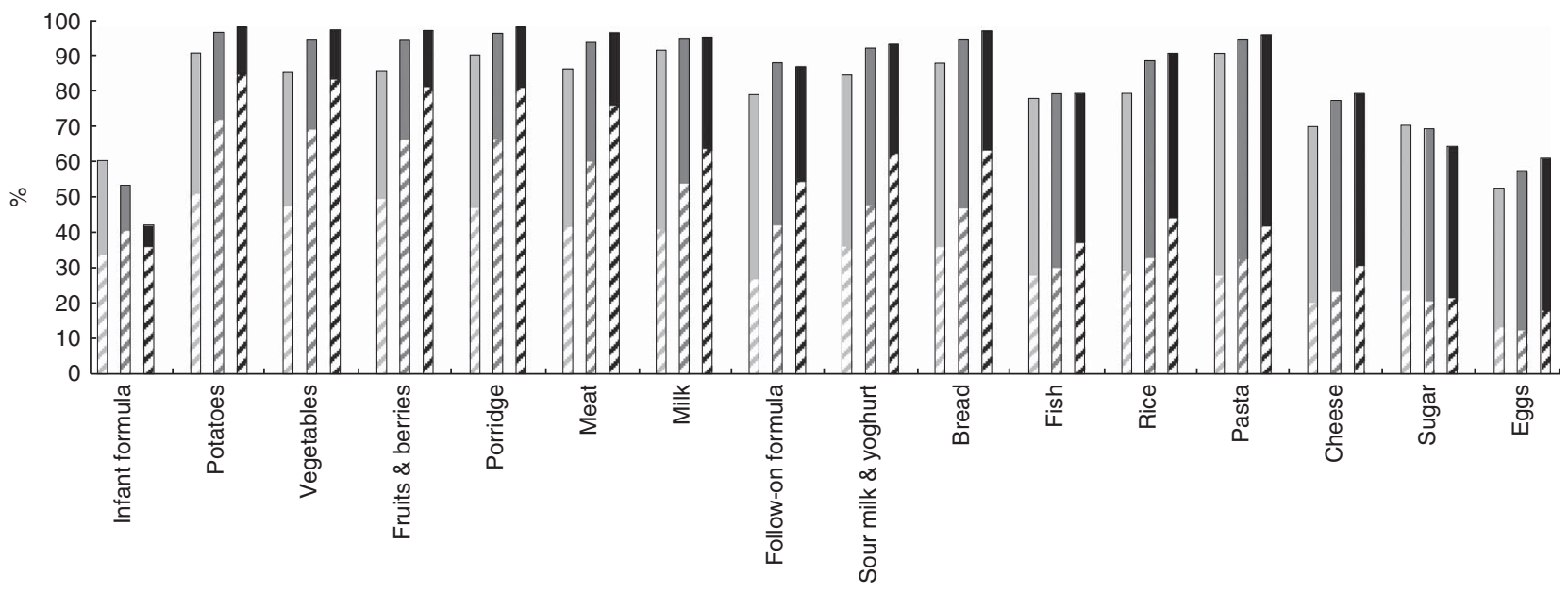

Fig. 2 Percentage of children introduced to complementary foods during the first 12 months by maternal education, All Babies in Southeast Sweden (ABIS) study ( $n$ 9727): $\square$, low education; $\square$, intermediate education; $\mathbf{q}$, high education. Hatching shows percentage introduced to complementary foods during breast-feeding (at least $30 \mathrm{~d}$ overlap)

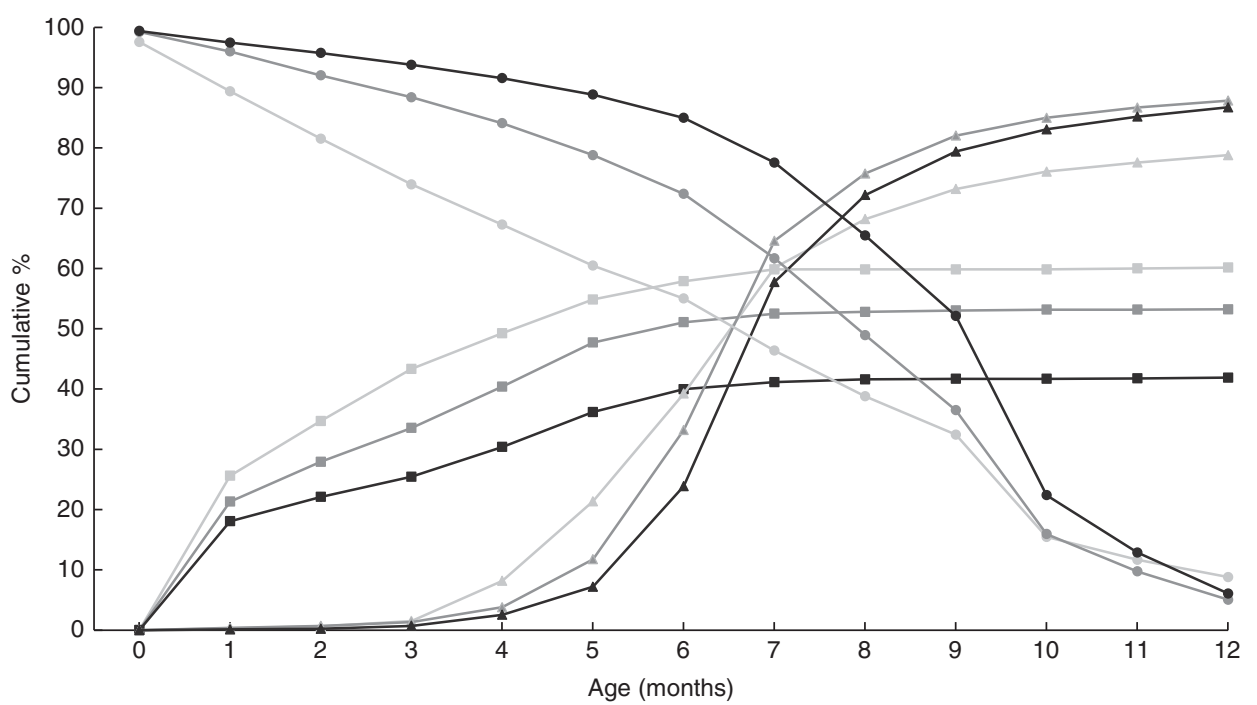

Fig. 3 Cumulative proportion of infants introduced to infant formula and follow-on formula and the proportion of infants being breastfed during the first 12 months by maternal education, All Babies in Southeast Sweden (ABIS) study ( $n$ 9727): - - , infant formula, low education; $-\_$, follow-on formula, low education; -- , breast-feeding, low education; $-\leftarrow$, infant formula, intermediate education; $\rightarrow$, follow-on formula, intermediate education; -- , breast-feeding, intermediate education; $\rightarrow-$, infant formula, high education; $\_$, follow-on formula, high education; $-\longrightarrow$, breast-feeding, high education. Differences in proportions breastfed, introduced to infant formula and follow-on formula across categories of maternal education at age 4 and 6 months, respectively, were tested and were significant at both ages for all variables $(P<0.001)$

specific foods and food groups as well as introduction during concurrent breast-feeding. We found that most children were introduced to complementary foods appropriately with regard to timing of introduction according to the recommendations at that time. However, the proportions of children introduced to fish and eggs during their first year were considerably lower than for other common foods and food groups. Furthermore, introduction before 16 weeks ( 4 months) of age was seen for about one in four infants, despite the recommendations to start introduction of complementary foods no earlier than at 4 months of age. This finding is in agreement with what Hörnell et al. found in a smaller cohort of Swedish infants born 1989 to 1992, where about one out of three was introduced to solids before 4 months of age ${ }^{(24)}$.

In relation to the relatively scarce data existing on the timing of introduction of complementary foods in Nordic countries, the results from the present study seem to be consistent with previous studies. Andrén Aronsson et al. reported from an international multicentre study that infants in Sweden and Finland were introduced to potatoes and roots, fruits and berries and cereals during 


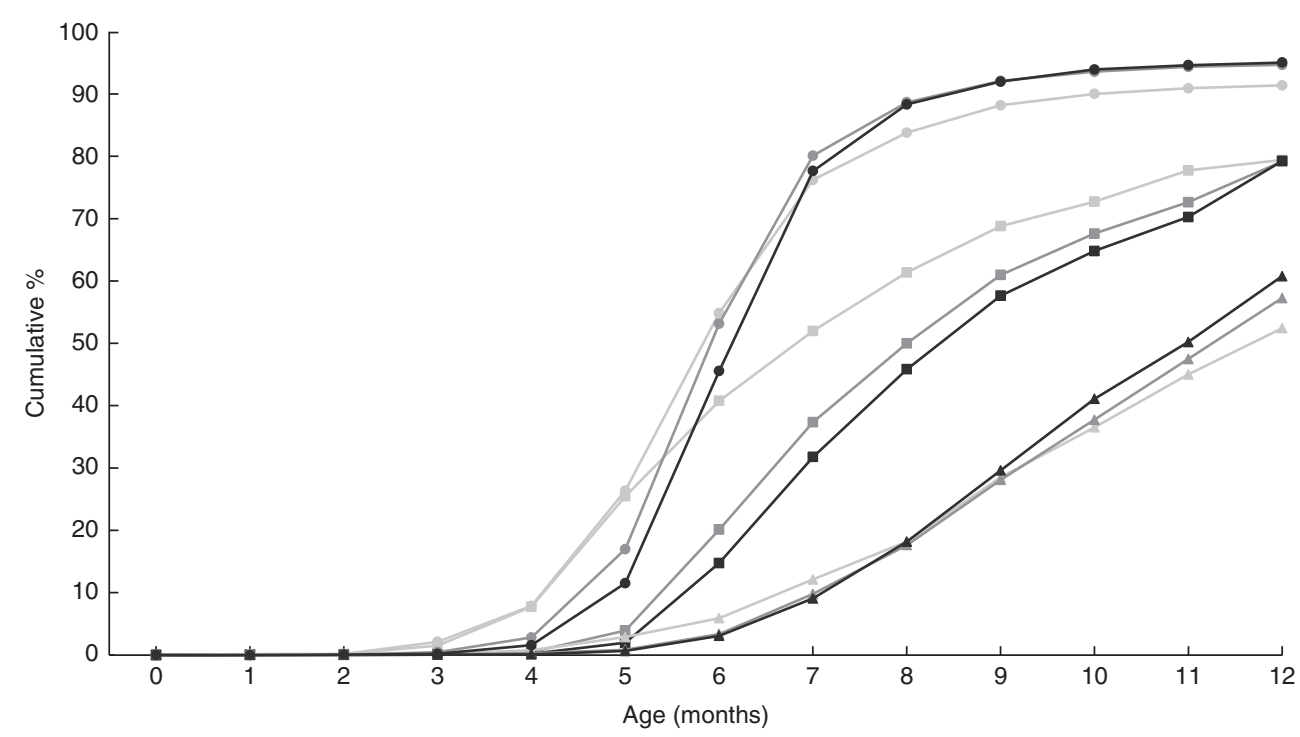

Fig. 4 Cumulative proportion of infants introduced to fish, eggs and milk products during the first 12 months by maternal education, All Babies in Southeast Sweden (ABIS) study ( $n$ 9727): $\_-$, fish, low education; —— , eggs, low education; $-\infty$, milk/sour milk/ yoghurt, low education; - - fish, intermediate education; -- , eggs, intermediate education; -- , milk/sour milk/yoghurt, intermediate education; $-\longrightarrow$, fish, high education; $-\leftarrow$, eggs, high education; $\rightarrow$, mil/sour milk/yoghurt, high education. Differences in proportions introduced to milk, eggs and fish across categories of maternal education at age 4 and 6 months, respectively, were tested and were significant at both ages for milk products and fish $(P<0.001)$ but not for eggs $(P>0.001)$

months 4 and $5^{(25)}$, and Erkkola et al. reported from a Finnish study that infants were introduced to potatoes, roots, fruits and berries during month 4 , to cereals and meat at age 5 months, to fish at age 7 months and to milk products during month $10^{(26)}$. However, both these studies collected data on introduction of complementary foods up until the age of 24 months, somewhat reducing the comparability with our study. Furthermore, while our sample is population-based, these two previous studies investigated cohorts with susceptibility for type 1 diabetes $^{(25,26)}$. In our previous paper on breast-feeding and introduction of solid foods ${ }^{(18)}$ we used retrospective data collected at a follow-up visit when the child was about 1 year old, while we in the present paper use data collected consecutively during the first year. When comparing our previous results based on retrospective data ${ }^{(18)}$ with our present results based on prospective data, parents seem to recall earlier introduction of porridge and follow-on formula when reporting retrospectively as compared with prospectively, while length of breast-feeding seems to have high consistency.

Maternal education was associated with introduction of complementary feeding in several ways. Early introduction occurred twice as often in infants of mothers with low education as compared with infants of mothers with high education. Despite mothers with lower education introducing foods to their infants earlier, fewer did this during concurrent breast-feeding. This may seem contradictory but is probably explained by shorter duration of breastfeeding in mothers with lower education, as shown in a previous publication on the ABIS cohort ${ }^{(20)}$. Previous research has also shown low parental education to be associated with earlier introduction of complementary foods in infants ${ }^{(21-23,25,26)}$ and that both younger maternal age $^{(21-23,25)}$ and maternal smoking ${ }^{(21-23,25,26)}$ also predict earlier introduction of complementary foods. Post hoc analyses of the present results showed that mothers with lower education were both younger and more likely to smoke during pregnancy, as compared with mothers with intermediate or high education. These three characteristics likely often coexist and further enhance the odds of early introduction of complementary foods. Contradictory to the association between lower maternal education and earlier introduction, lower maternal education was also associated with lower proportions of children introduced to the investigated foods and food groups at 1 year of age, which could mean that these infants consume only a limited number of foods. Why lower education is associated with a lower compliance to public health recommendation is a question that remains to be answered, but in the case of low maternal education and early introduction of complementary foods this may have future health implications for the children. Early introduction of complementary feeding may be associated with increased risk of childhood overweight ${ }^{(6)}$ and type 1 diabetes mellitus $^{(7)}$, while early introduction of specific allergens may decrease the risk of allergy ${ }^{(8)}$.

The ABIS cohort was recruited at the end of the 1990s and we need to take both changes in breast-feeding rates and changes in infant feeding recommendations into account when interpreting our findings with regard to what we could expect for today's infants. At the end of the 1990s breast-feeding rates in Sweden reached their peak. At this time, more than $80 \%$ of Swedish infants were breast-fed at age 4 months and $70 \%$ were breast-fed at 
6 months of age ${ }^{(28)}$. Since then a decline in breast-feeding rates of about 10 percentage points has occurred in Sweden. When looking at full breast-feeding the rate has declined even more, from about $70 \%$ at age 4 months at the end of the $1990 \mathrm{~s}^{(29)}$ to about $50 \%$ in $2014^{(28)}$. At age 6 months, the corresponding figures are $40 \%{ }^{(29)}$ and $15 \%{ }^{(28)}$. These rates are in accordance with what has been shown in the ABIS cohort ${ }^{(18)}$, with the exception of a much lower rate of exclusive breast-feeding at age 6 months in the ABIS cohort where only about $10 \%$ of the infants were exclusively breast-fed at age 6 months ${ }^{(18)}$. This difference is however most likely explained by differences in the definition of exclusive breast-feeding. Since the late 1990s breast-feeding recommendations have changed and exclusive breast-feeding is now recommended for the first 6 months ${ }^{(17)}$. If the child is interested, tiny tastes of any food could be given from 4 months of age, but without competing with the breast-feeding ${ }^{(17)}$. It could be speculated that more infants are introduced to infant formula today and that they are introduced earlier, because of shorter duration of exclusive breast-feeding and because the present recommendations stress that complementary meals should not be introduced before the age of 6 months. Furthermore, it could be speculated that infants are introduced to complementary foods later today than in the late 1990s and thus also to a lesser extent during concurrent breast-feeding. Later introduction may not however apply to some specific foods, such as fish and eggs. Previously, allergy preventive recommendations were given to families with atopic heredity recommending them to postpone introduction of fish and eggs until 9-12 months of age ${ }^{(12-14)}$. It is probable that this recommendation explains the fact that as many as 20 and $40 \%$, respectively, of the infants of ABIS were not introduced to fish and eggs during their first year, while only about $5 \%$ of the infants were not introduced to for example potatoes, fruits, vegetables, cereals, meat and milk products. Perhaps this recommendation was adopted not only by the families with atopic heredity, but also by other families. In the present study higher maternal education was associated with later introduction of fish, while no such gradient was seen for eggs. A post hoc analysis showed a positive association between reported atopic heredity and higher maternal education, which could explain why fish was introduced later to infants of mothers with high education. However, why timing of egg introduction was not affected is not clear. Today, no general recommendation is given with regard to introduction of fish and eggs to infants with atopic heredity ${ }^{(17)}$.

Strengths of the present study include the prospective design and a large population-based sample with a high participation rate. Furthermore, the design of the food diary and the successive completion of this throughout the first year ensure detailed information about introduction of several foods and food groups. The study is not without its weaknesses however, and the fact that we rely on self-reported data has to be accounted for. Another limitation is that the food diary was limited to a specific set of foods and food groups; but most likely these groups did cover the majority of the foods consumed during the infants' first year.

\section{Conclusion}

In conclusion, most infants were introduced to complementary foods in a timely fashion. Foods introduced earlier than recommended, i.e. before 4 months of age, were generally foods that were recommended to be introduced first. Maternal education was found to clearly influence introduction of complementary feeding and low maternal education was associated with both earlier introduction of complementary foods and less introduction during concurrent breast-feeding. Still, our results indicated that infants of mothers with low education were exposed to fewer foods at 12 months of age. The ABIS study offers unique potential for investigations of introduction of complementary foods in relation to several health outcomes.

\section{Acknowledgements}

Acknowledgements: The authors are grateful to all children and parents who participated in ABIS. Financial support: This study as a part of the ABIS project was supported by the Swedish Child Diabetes Foundation (Barndiabetesfonden); Novo Nordisk Foundation; The Research Council of Southeast Sweden (FORSS); Swedish Research Council (grant number K2005-72X-11242-11A); and ALF/ County Council of Östergötland. The funders had no role in the design, analysis or writing of this article. Conflict of interest: None. Authorship: J.L. and H.K.B. acted as equivalent senior authors. J.L. was the principal investigator in the ABIS study, constructed questionnaires and collected all data. S.K. and H.K.B. formulated the research questions. S.K. was responsible for the statistical analyses. S.K. was the primary author of the paper and wrote the article with contributions from J.L. and H.K.B. All authors read and approved the final manuscript. Ethics of human subject participation: This study was part of the ABIS study which has been approved by the Research Ethics Committees of the Faculty of Health Sciences, Linköping University and the Medical Faculty of Lund University. Mothers gave their consent after careful written as well as oral information and information via videotape.

\section{References}

1. World Health Organization (2001) 54th World Health Assembly: Global Strategy for Infant and Young Child Feeding. Geneva: WHO. 
2. World Health Organization \& UNICEF (2003) Global Strategy on Infant and Young Child Feeding. Geneva: WHO \& UNICEF.

3. Domellöf M, Braegger C, Campoy C et al. (2014) Iron requirements of infants and toddlers. J Pediatr Gastroenterol Nutr 58, 119-129.

4. World Health Organization (2003) Guiding Principles For Complementary Feeding of the Breastfed Child. Geneva: WHO.

5. Harris G \& Coulthard H (2016) Early eating behaviours and food acceptance revisited: breastfeeding and introduction of complementary foods as predictive of food acceptance. Curr Obes Rep 5, 113-120.

6. Pearce J, Taylor MA \& Langley-Evans SC (2013) Timing of the introduction of complementary feeding and risk of childhood obesity: a systematic review. Int J Obes (Lond) 37, 1295-1306.

7. Nucci AM, Virtanen SM \& Becker DJ (2015) Infant feeding and timing of complementary foods in the development of type 1 diabetes. Curr Diab Rep 15, 62.

8. Ierodiakonou D, Garcia-Larsen V, Logan A et al. (2016) Timing of allergenic food introduction to the infant diet and risk of allergic or autoimmune disease: a systematic review and meta-analysis. JAMA 316, 1181-1192.

9. Akobeng AK, Ramanan AV, Buchan I et al. (2006) Effect of breast feeding on risk of coeliac disease: a systematic review and meta-analysis of observational studies. Arch Dis Child 91, 39-43.

10. Szajewska H, Shamir R, Mearin L et al. (2016) Gluten introduction and the risk of coeliac disease: a position paper by the European Society for Pediatric Gastroenterology, Hepatology, and Nutrition. J Pediatr Gastroenterol Nutr 62 507-513.

11. Ludvigsson J, Gustafsson-Stolt U, Liss PE et al. (2002) Mothers of children in ABIS, a population-based screening for prediabetes, experience few ethical conflicts and have a positive attitude. Ann N Y Acad Sci 958, 376-381.

12. National Institute of Public Health (1996) Mat för spädbarn 0-12 månader (in Swedish). Stockholm: Folkhälsoinstitutet.

13. National Institute of Public Health (1998) Mat för spädbarn o-12 månader (in Swedish). Stockholm: Folkhälsoinstitutet.

14. National Food Agency Sweden (1999) Mat för spädbarn råd och inspiration till föräldrar (in Swedish). Stockholm: Livsmedelsverket.

15. Ivarsson A, Persson LA, Nyström L et al. (2000) Epidemic of coeliac disease in Swedish children. Acta Paediatr 89, $165-171$.
16. Lindberg T (1996) Gluten. Changed recommendations for infant care. Society of Pediatricians, Sweden. Lakartidningen 93, 4396-4397.

17. National Food Agency Sweden (2012) Good Food for Infants Under One Year. Uppsala: Livmedelsverket.

18. Brekke HK, Ludvigsson JF, van Odijk J et al. (2005) Breastfeeding and introduction of solid foods in Swedish infants: the All Babies in Southeast Sweden study. Br J Nutr 94, 377-382.

19. Brekke HK, van Odijk J \& Ludvigsson J (2007) Predictors and dietary consequences of frequent intake of high-sugar, low-nutrient foods in 1-year-old children participating in the ABIS study. Br J Nutr 97, 176-181.

20. Ludvigsson JF \& Ludvigsson J (2005) Socio-economic determinants, maternal smoking and coffee consumption, and exclusive breastfeeding in 10205 children. Acta Paediatr 94, 1310-1319.

21. Rebhan B, Kohlhuber M, Schwegler U et al. (2009) Infant feeding practices and associated factors through the first 9 months of life in Bavaria, Germany. $J$ Pediatr Gastroenterol Nutr 49, 467-473.

22. Schiess S, Grote V, Scaglioni S et al. (2010) Introduction of complementary feeding in 5 European countries. J Pediatric Gastroenterol Nutr 50, 92-98.

23. Kronborg H, Foverskov E \& Vaeth M (2014) Predictors for early introduction of solid food among Danish mothers and infants: an observational study. BMC Pediatr 14, 243.

24. Hörnell A, Hofvander Y \& Kylberg E (2001) Introduction of solids and formula to breastfed infants: a longitudinal prospective study in Uppsala, Sweden. Acta Paediatr 90, 477-482.

25. Andrén Aronsson C, Uusitalo U, Vehik K et al. (2015) Age at first introduction to complementary foods is associated with sociodemographic factors in children with increased genetic risk of developing type 1 diabetes. Matern Child Nutr 11, 803-814.

26. Erkkola M, Salmenhaara M, Nwaru BI et al. (2013) Sociodemographic determinants of early weaning: a Finnish birth cohort study in infants with human leucocyte antigenconferred susceptibility to type 1 diabetes. Public Health Nutr 16, 296-304.

27. Nygren M, Carstensen J, Koch F et al. (2015) Experience of a serious life event increases the risk for childhood type 1 diabetes: the ABIS population-based prospective cohort study. Diabetologia 58, 1188-1197.

28. National Board of Health and Welfare (2016) Statistik om amning 2014 (in Swedish). Stockholm: Socialstyrelsen.

29. National Board of Health and Welfare (2015) Amning och föräldrars rökvanor - Barn födda 2013 (in Swedish). Stockholm: Socialstyrelsen. 